\title{
BOOSTING THE EDUCATION QUALITY USING THE MODEL GAPS AND 8P FRAMEWORK FOR HIGHER EDUCATIONAL INSTITUTIONS IN INDIA
}

KEY WORDS: Higher

Education, Marketing Strategy, GAPs Model, EduQual, Marketing mix, 8P's.

\section{Vignesh* \\ Dr. V. Padmaja}

Ramaiah Institute of Management Bangalore. *Corresponding Author

Associate Professor, Ramaiah Institute of Management Bangalore.

Advanced education is getting extremely severe in the globalised world of the present century, and large colleges must advance their own organisations both locally and internationally. Advanced curriculum is one of the most important aspects of a nation's preparation. The key objective of advanced education is to produce fresh knowledge, to analyse study chips on different topics of social progress, to anticipate the needs of the economy and to train extremely talented professionals. The study would investigate the methods of ads submitted by higher educational bases in India. The basic aim of this review is to explore the essence of higher education in India. In any event, the report underlines the discernment and conclusions of the analysis about the current accessible and private company education structures and emerging problems and challenges explored by specialised education organisations. For the analysis of knowledge, both subjective and quantitative techniques were used. The study results demonstrate the different facets of advanced schooling, their efficiency and their present affordability as well as their obvious higher-education advantages. This paper further examines the implications of the expanded distance paradigm for evaluating the essence of instruction (EduQual). The regular five Holes in institutional Deficiencies contain two new Differences. It was observed that the two additional Differences are connected to the organisation of higher educational foundations. The success of understudies with the direction provided greatly impacts the verbal correspondence of the understudies. The layout of the examination was noticed that two essential factor events had an effect on the choices of the understudies: human variables and structural components. This research also reveals the impact of 8Ps frameworks. The factor results of the 8Ps segments are radical in ensuring the completion of the analysis. Estimating the essence of their governments is therefore a big move for all organisations who relate to the components of importance which should be discussed and that give foundations the chance to increase an essential position in the knowledge view.

\section{INTRODUCTION}

With respect to higher education in India, an observable pattern is an expanding rivalry among colleges and higher education establishments to draw in understudies. The serious weight and developing number of training suppliers have constrained higher instructive organizations to search for more serious showcasing techniques to go after understudies in their separate enrolment markets. Rivalry among higher education foundations is to a great extent because of an oversupply of understudy places and easing back interest from reasonably qualified understudies. Subsequently, the administration of the higher education part is looking to rebuild their vital positions. Speculations and practices in business technique improvement, as utilized in the revenue driven business area give a premise to inventive methodologies; to methodology advancement, in any case, they don't address the far-reaching arranging needs of the advanced education segment. Instructive establishments face promoting issues. Many face changing understudies needs and cultural desires, expanding rivalry for scant customer and subsidizing assets, and boundless money related weights. One outcome is that instructors are regularly compelled to truly investigate showcasing to perceive what this order may offer to keep their foundations practical and significant. Simultaneously, numerous instructors are moving toward advertising with alert. Higher education is getting more serious from an assortment of viewpoints. Inside, establishments must oversee costs, while simultaneously there's a developing need to practice and convey an interesting message to a growing commercial center. From the candidate's vantage, understudy possibilities are confronted with more training choices than any other time in recent memory. A strong promoting technique can, hence, legitimately influence the main concern of a school, college, or proceeding with instruction organization through estimation and comprehension of its situation in the commercial center and by killing shortcomings and expanding upon qualities.

\section{BACKGROUND OFTHE STUDY}

The education sector has been competitive and diverse in recent years. The explanation is that there are multiple commercial movements attempting to influence the educational system. Consequently, rivalry between universities is rising and continues so long as the number of students in public and private schools is decreasing, attributable also to newer higher education institutions. The elements of marketing mix will affect the competitiveness of a company (product, price, location, advertising, staff, process and physical proof, promise). It has been proposed that, because of the distinctive features of services and the superiority of expertise and credence, selling in the service sector (as at universities) is very difficult. Higher education (HE) is a fascinating and significant study background since $\mathrm{HE}$ is rising in marketing orientation across the world and students are being increasingly customer.

For decreases, colleges have been even more competitively advertisement oriented to meet their targets. Adding to the growth and promotion of higher education a broad variety of communication strategies have been utilised in the field.

\section{LITERATURE REVIEW}

Marketing offers techniques to equate what the organisation is doing with its specified purpose and objectives. Marketing helps find challenges and formulate a solution to help the organisation accomplish its task. In highlighting the value of assessing and addressing consumer expectations, marketing aims to deliver an increased degree of customer support and satisfaction. It offers a focused approach to maximising the appeal of the requisite services for the teachers, staff, donors, contributions and grants. Marketing focuses rational product creation, packaging, marketing, and sales control and planning (Kotler \& Fox, 1985).

Cheng (cited in Cheng and Tam, 1997, p.23) defines quality of education as "the character of the collection of elements in the input, process and output of the education system which provides services that fully satisfy both internal and external strategic constituencies by satisfying their express and implied expectations." The seven quality education models suggested by Cheng and Tam (1997) for assessing the definition of quality education are: (1) target and definition model; (2) resource-input model; (3) method model; (4) 
model of satisfaction; (5) model of legitimacy; (6) model of loss of challenge model; and (7) model of organisational learning. Each of the models of quality education has its own specific characteristics, benefits and limitations which define the aspects of quality education in their own way and yet are interlinked (Tam and Cheng, 1996). These models help the tertiary institution's administrators to determine their own level of education (Tam and Cheng, 1996).

Marketing is planning and enforcing the creation, selling, promotion and delivery of concepts, products, and services to establish markets which fulfil individual and organisational objectives (Berkowitz, Kerin, Hartley and Rudelius, 1997). To represent consumers and sellers alike, marketing aims to explore and fulfil the desires and expectations of prospective customers.

\section{Marketing is designed to bring forward four main benefits:}

1. Big achievement fulfils the missions of the institution.

2. Improved public trust at the institution.

3. Improved communications portfolio attention.

4. Improved Advertisement Efficacy.

The definition of quality in higher education is not clearly established (Cheng and Tam, 1997; Pounder, 1999). According to Mukhopadhyay (cited in Sahney, Banwet and Karunes, 2004, p.149), various scholars, such as the word "excellence in education" (Peters andWaterman, 1982), "added value" (Feigenbaum, 1951), "fitness of educational result and user experience" (Juran and Gryna, 1988), "specifications" (Gilmore, 1974; Crošby, 1994 ) identified consistency of education by various scholars.

There is no question that HE offers a major motivation for the very economy of the individual and the economies of the nations in which the educated work. Slope, Hoffman and Rex (2005) identify two ways of impacting people 's monetary wellbeing by advanced schooling. Initially, HE offers undergraduates pursuing cutting-edge training moneyrelated and non-budgetary advantages. Undergraduate gains are associated for their instructive achievement. Those with a high school earn more than those with a four-year college diploma and those with a basic school qualification, and those with advanced qualifications benefit more from those with just bachelor degrees, etc. About the fact that HEs deliver fleeting benefits, understudies often profit from their chance to enter and full HE. As Baum and Bowen (2004) and Bowen (1997) show, the advantages of drawn-out research for an understudy in and of completing an ET include higher wages, a more rewarding career, greater well-being, healthier life, more skilled transactions and less risk of worklessness.

\section{OBJECTIVES OFTHE STUDY}

The following objectives were framed for the purpose of the study:

- To define a higher education marketing mix.

- Assess of the particular consequences of the GAPs concept for the standard evaluation of education systems.

- Describe the identification problems which can effectively provide the higher education entities with successful CRM and word - of - mouth contact.

\section{METHODOLOGY AND INFORMATION-SOURCES}

Qualitative analysis approach is used for this research. This is a method of analytical analysis to evaluate the factors impacting education quality by utilising the GAP and 8P model. While no questionnaire study was carried out in order to obtain the primary data, the interview method was considered though some structured questions. Focus group discussions also helped in understanding certain qualitative aspects of the study. Experts from both the technical and administrative divisions of educational institutions were included. In this respect, about 20 academicians and research scholars from the relevant area have been consulted. Data was also collected from secondary sources. It was collected though some secondary details to render the study more meaningful research articles from high impact factor journals and from various sources including Scopus, JGate and other renowned publications. Different articles published in magazines and newspapers were also referred for the purpose of the study.

\section{SERVICE MARKETING MIX FOR EDUCATIONAL INSTITUTIONS.}

The institution has different characteristics than other types of educational institutions. Higher education is an unconventional form of administration as opposed to other well-known administrations that needs more modification that care of its own view combination (The Holocaust, 2011). 'Ad mix' is the aggregate term used to describe the different kinds of decision-making that organisations may take in the whole phase of selling to the public an object or an administration. The $4 \mathrm{Ps}$ are one way to describe the advertisement mix and were first recorded in 1960 by E. J. McCarthy., currently the most common method. According to the board administration, this blend might be adjusted and applicable in a specific way. Be that as it may, In request to plot effective showcasing of administrations the 8Ps methodology were presented - including individuals, physical proof, and procedure to the conventional advertising blend In the light of the way that promoting can impact the buyer's conduct and the administrations showcasing blend can help the executives foundations can mix in building up a comprehensive and carefully conceived Program or needbased assistance being offered, if there should be an occurrence of private instructive establishments now and then the understudies go about as the main help experience. In such instances, textual communication becomes important for the institutional integrity and the development of understudies. To face these risks of systemic integrity, knowing and worrying regarding the 8Ps at the heart of assistance preparation is a major challenge.

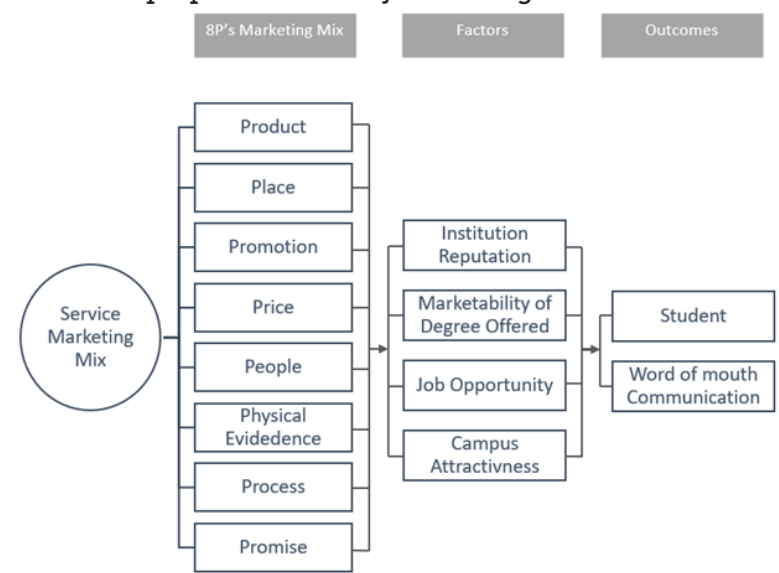

Figure-1: A methodological approach and findings for educational institutions in the Service Marketing Mix.

\section{Product:}

- Courses Provided- choice and available selection of courses.

- Quality Standard- material of course value and qualifications of the instructors.

- Brand Name- organisation and degree acknowledgement and appreciation provided

- Post Transactional Program-the student support facility for providing similar certificates and other paper work.

2. Place:

- Place- the institution's place and transport facilities, and transport comfort and availability.

- Access- Accessibility to find details for the students and 
their parents.

- Distribution Networks- the institution's subsidiaries span a broad field of delivery and expansion of operation.

- Distribution range-Distance learning distribution and region degree.

\section{Promotion:}

- Advertisement- company ads in a range of channels to build recognition about the degrees being provided and support being delivered.

- Direct marketing- connectivity over Text messaging and social media and e-mail networks.

- Promotion- Organizing on various national and international gatherings, lectures, contests, career fairs, and cultural events.

\section{Price:}

- Education expense-the fulfilment of the whole course.

- Scholarships/Discounts - discounts and available scholarships from the institution which reduce the total cost of education.

- Commissions- Additional incentives of representing the company through word of mouth.

- Payable Terms- the payment terms and conditions and the flexibility thereof

- The expected importance of the student's- the benefit that a student derived from the service

- Quality / price relation- the relationship between the institution's received values and the amount they paid for it.

\section{People:}

- Faculty- the educational credentials and reputation of the institution's faculty representatives

- Teacher preparation - the teacher's growth and advancement by the funding of separate professional improvement training sessions

- Management personnel-performance and honesty, helping administrative personnel and their behaviour towards students

- The extent of engagement of teachers in the policy making of education and staff preparation

- Contact Meeting- the effectiveness of the contact meeting to establish a picture of the school before the investigators, i.e. students, parents etc.

\section{Physical evidence:}

- Environment- the atmosphere and learning setting, noise level, room and relaxing scope etc.

- Furnishings- The chairs, the furnishings, the laboratories, etc.

- Design- the overall institutional setup and the campus elegance

- Lab infrastructure- functional research equipment, research laboratory technology, electronic laboratories, internet connectivity, etc.

\section{Process}

- Student Cooperation- the extent of communication of the students, relationship to the teachers and administrative body.

- Teaching Process- Teaching mechanism, affecting the learning of self-test, digital lectures and the learning phase

- Managerial discretion- managerial discretion and the overall involvement of the students in the course of learning.

- Student engagement- engagement of students in numerous events and coordination of ability to enhance student organisational capacities

- The organised flow of events - the tasks are structured in order to best explain the behaviours.

\section{Promises:}

Transformation of creative development in centre teaching, for example, enabling internet learning systems, smartphone software and immersive teaching technologies.

Greater adaptability in the transmission of content, thus maintaining the usability of courses for participants as logically anticipated.

Enable understudies to focus on their desires, to provide a heritage depending on the creation of the module itself and ensure that the modules are present and appropriate for understudies.

\section{THE EXTENDED GAPS MODEL FOR EDUCATIONAI INSTITUTIONS}

The basic GAP model as proposed by Zeithaml, Bitner and Parasuraman of USA (1988) had 5 GAPs applicable for all service quality analysis. But an extended GAP model can also be developed applicable for higher educational institutions. This additional GAP can have also have a significant influence on the analysis of education quality.

\section{The GAP Side Teaching (GAP Institution)}

Gap 1: The difference between student expectations and the interpretation of student expectations by the faculty.

\section{GAP-1 Causes:}

- Lack of awareness and diversification of the student 's view on education curricula.

- Lack of studies on the experience of students and aspects of the level of education.

- Lack of adequate contact and cooperation between staff and students.

- Excess administrative structures between front-end workers and the staff at the upper stage.

Gap 2: Difference in student expectations of the staff and student-driven programme design \& teaching requirements.

\section{GAP-2 Causes:}

- Student delays have pushed curriculum expectations.

- Undefined series of requirements intended to be delivered by faculty members and administrative personnel to students.

- Lack of service implementation (process management) tracking method to concentrate on the needs of students.

- Lack of focus on providing better service.

- The lack of a structured mechanism for developing new courses which may help link students and faculty members.

Gap 3: Difference between the configuration and requirements of student education (teaching) and the implementation of the education.

\section{GAP-3 Causes:}

- Inadequate recruiting of professors and support personnel.

- Misunderstanding and dispute of roles between faculty members and administrative personnel.

- Improper assessment and payment of community members.

- Lack of capacity for enhanced service management, collaboration and joint study among organisation employees.

- failure to advise students of their position and responsibility for enhancing the institution's educational facilities.

Gap 4: Difference in effective implementation and external student / parent interactions (promised teaching outcomes).

GAP-4 Causes: 
- Inadequate CRM to control the student's service requirements.

- Educational standard and other associated considerations such as work selection, business attachment, etc.

- Inadequate communication between teaching and nonteaching personnel.

- Institutional differences, policies, education in different affiliated schools, institutions, standard and other classes.

- Lack of promotion and insufficient external media contact to meet target markets.

Gap 5: Difference between student standards views of the staff and the student expectations of administration.

\section{GAP-5 Causes:}

- Lack of appropriate communication between teaching members and administrative workers (interactive marketing).

- Improper interaction between staff and administrators regarding the aspirations of the students.

- Uncertainty and disagreement between faculty members and administrative employees over their position.

Gap 6: Difference in student preferences and student administration perceptions.

\section{GAP-6 Causes:}

- Lack of appropriate communication between the administration and students (interactive marketing).

- Failure to respond quickly to the students' inquiries and meeting in the event of service failure.

- Several management personnel preparing to fulfil the students' specifications.

- unwillingness to train college support workers

GAP-7: the differences between the service perceptions of the student and the service perception of the student.

GAP-7 Causes:

- The first impression a student gets while engaging at the time of enrolment with faculty members and administrative staff by mobile or face-to-face.

- Approach to the first gatherings (administrative staff) and to the student's request from the faculty representatives, to issue students, to the student's request.

- Over-promising provision by the universities (both academic and support services) to draw students to the buildings.

- Student proportions used for determining level of operation. This creates an essential gap in this field.

\section{Suggestions}

Several marketing techniques are also proposed for higher education institutions in India:

- Marketers must then classify correctly their target audiences and recognise the desires and expectations of the target market segments.

- In order to satisfy the interests of students, university operators should recognise the consistency of the instruction, academic photographs and campus atmosphere in order to draw pupils.

- Holistic exposure - gives students a special opportunity. This provides an opportunity to meet and take a broader range of students, particularly from other faculties Participates in a number of university programmes. In fact, this is absent in private organisations.

- Picture and image - Marketing can be directed at specific audiences including pupils, peers and family.

- Dissemination of knowledge - TV, radio, educational fairs, company members' national tours, etc.

- Facilities - expanded usage of interactive technologies and/or ICT in all areas of implementation of education services.

- Academic workers-focus on high-quality recruits and training professionals with relevant study and industry backgrounds.
Scope for further research

Future research can utilise focus groups or an extensive analysis to analyse the organizations' 'marketing thought.' Researchers may even suggest investigating others aspects such as psychological considerations, family background, academic success etc. in the student's decision-making process. Another challenge worth discussing is the Connection between university option and post-purchase behaviour, academic performance and degree of satisfaction.

\section{CONCLUSION}

Higher education implies a nation citizen 's primary right. This sector will effectively respond to an economy 's critical needs. This sector affects society as a whole through some strongly interconnected causes, namely the growth of societal, economic, technical, human capital and so forth. In order to promote these progressions and have sufficiently skilled workers, higher education reform is an essential activity. The suitability of higher education institutions, both locally and remotely, increases. Higher education also requires time and room in terms of affordability and consistency. The reorientation of the curriculum and the introduction of technical and employment-oriented courses are required to preserve and increase quality in higher education. The current educational framework at the State University of India is in a precarious condition because there are no plans, lack of a mix of expertise and experience, lack of capability and efficiency for graduates. In the new dynamic consumer economy, it lacks its articulation and prestige, which renders it fragile. The university would not now retain the continuity and the level of teaching, study and social responsibility it had before.

\section{REFERENCES}

1. Faganel, Armand "Quality Perception GAP Inside the Higher Education Institute", INTERNATIONAL JOURNAL of ACADEMIC RESEARCH Vol. 2. No. 1. January 2010

2. Kotler, P. and Fox, K.F.A. (1985). Strategic Marketing for Educational Institutions, NJ:Prentice-Hall,Englewood Cliffs

3. Juran, J. M., and Godfrey, A. B. (2000). Juran's quality handbook, (5th edn), Singapore:McGraw-Hill.

4. Kotler, P., Fox, K. (1995) Strategic Marketing for Educational Institutions. New Jersey:Prentice-Hall.

5. Soedijati \& Pratminingsih (2011). The impacts of the marketing mix on students" choice of University Study case of the private university in Bandung, Indonesia, Proceedings of a 2nd international conference on business and economic research (2nd ICBER 2011).

6. Palmer, A. (2001). Principles of Services Marketing, 3 rd Ed., London: McGrawHill.

7. Cheng, Y.C. (2003). Ouality assurance in education: internal, interface, and future. Quality Assurance in Education, 11(4),202-213

8. Feigenbaum, A.V. (1951). Quality control: principles, practice and administration. NewYork: McGraw-Hill.

9. Zeithaml,V.A., Parasuraman, A. \& Berry, L.L. (1985) Problems and strategies in services marketing, Journal of Marketing, 49(4),33-46.

10. Zeithaml, V.A., Parasuraman, A. \& Berry, L.L. (1990), Delivering Quality Service: Balancing Customer Perceptions and Expectations, New York, NY: The Free Press, New York, NY.

11. Berkowitz, E. N, R., A., Kerin, W. Rudelius (1997). Marketing. 5th Ed. Irwin McGrawHill. 